\title{
ON STEVIĆ-SHARMA OPERATORS FROM HARDY SPACES TO STEVIĆ WEIGHTED SPACES
}

\author{
Zhitao GuO AND Yonglu Shu
}

Abstract. In this paper, we investigate the boundedness and compactness of Stević-Sharma operator $T_{\psi_{1}, \psi_{2}, \varphi}$ from Hardy space $H^{p}$ to Stević weighted space $\mathscr{W}_{\mu}^{(n)}$ on the unit disk, and estimate the norm of $T_{\psi_{1}, \psi_{2}, \varphi}$ when it is bounded.

Mathematics subject classification (2010): 47B38, 47B33, 46B50, 30H10.

Keywords and phrases: Stević-Sharma operator, Hardy space, Stević weighted space, boundedness, compactness.

\section{REFERENCES}

[1] C. C. Cowen And B. D. MacCluer, Composition operators on spaces of analytic functions, Studies in Advanced Mathematics. CRC Press, Boca Raton, 1995.

[2] P. DuREn, Theory of $H^{p}$ Spaces, Academic Press, New York, 1970.

[3] Z. JiAnG, On Stević-Sharma operator from the Zygmund space to the Bloch-Orlicz space, Adv. Difference Equ. 2015, 228 (2015), 12 pp.

[4] W. Johnson, The curious history of Faàdi Bruno's formula, Amer. Math. Monthly. 109, 2 (2002), 217-234.

[5] H. LI AND Z. GUO, On a product-type operator from Zygmund-type spaces to Bloch-Orlicz spaces, J. Inequal. Appl. 2015, 132 (2015), 18 pp.

[6] S. Li And S. STEviĆ, Volterra-type operators on Zygmund spaces, J. Inequal. Appl. 2007, Art. ID 32124 (2007), $10 \mathrm{pp}$.

[7] S. Li AND S. STEVIĆ, Generalized composition operators on Zygmund spaces and Bloch type spaces, J. Math. Anal. Appl. 338, 2 (2008), 1282-1295.

[8] S. Li AND S. STEVIĆ, Products of Volterra type operator and composition operator from $H^{\infty}$ and Bloch spaces to Zygmund spaces, J. Math. Anal. Appl. 345, 1 (2008), 40-52.

[9] S. LI AND S. STEVIĆ, Weighted composition operators from Zygmund spaces into Bloch spaces, Appl. Math. Comput. 206, 2 (2008), 825-831.

[10] S. Li And S. STEVIĆ, Products of composition and differentiation operators from Zygmund spaces to Bloch spaces and Bers spaces, Appl. Math. Comput. 217, 7 (2010), 3144-3154.

[11] S. Li AND S. STEvić, Generalized weighted composition operators from $\alpha$-Bloch spaces into weighted-type spaces, J. Inequal. Appl. 2015, 265 (2015), 12 pp.

[12] Y. LiU AND Y. Yu, On Stević-Sharma type operator from the Besov spaces into the weighted-type space $H_{\mu}^{\infty}$, Math. Inequal. Appl. 22, 3 (2019), 1037-1053.

[13] B. SehBA AND S. STEVIĆ, On some product-type operators from Hardy-Orlicz and Bergman-Orlicz spaces to weighted-type spaces, Appl. Math. Comput. 233, (2014), 565-581.

[14] A. K. Sharma, Products of composition multiplication and differentiation between Bergman and Bloch type spaces, Turkish J. Math. 35, 2 (2011), 275-291.

[15] A. Shields AND D. Williams, Bounded projections, duality, and multipliers in spaces of analytic functions, Trans. Amer. Math. Soc. 162, (1971), 287-302.

[16] S. STEvić, Composition operators from the weighted Bergman space to the $n$th weighted spaces on the unit disc, Discrete Dyn. Nat. Soc. 2009, Art. ID 742019 (2009), 11 pp.

[17] S. STEVIĆ, On an integral operator from the Zygmund space to the Bloch-type space on the unit ball, Glasg. J. Math. 51, 2 (2009), 275-287. 
[18] S. STEvić, On an integral-type operator from logarithmic Bloch-type and mixed-norm spaces to Bloch-type spaces, Nonlinear Anal. TMA 71, (2009), 6323-6342.

[19] S. STEVIĆ, Composition operators from the Hardy space to the $n$th weighted-type space on the unit disk and the half-plane, Appl. Math. Comput. 215, 11 (2010), 3950-3955.

[20] S. STEVIĆ, On an integral-type operator from Zygmund-type spaces to mixed-norm spaces on the unit ball, Abstr. Appl. Anal. 2010, Art. ID 198608 (2010), 7 pp.

[21] S. STEvić, Weighted differentiation composition operators from $H^{\infty}$ and Bloch spaces to $n$th weighted-type spaces on the unit disk, Appl. Math. Comput. 216, 12 (2010), 3634-3641.

[22] S. STEVIĆ, Weighted differentiation composition operators from the mixed-norm space to the $n$th weigthed-type space on the unit disk, Abstr. Appl. Anal. 2010, Art. ID 246287 (2010), 15 pp.

[23] S. STEVIĆ, On some integral-type operators between a general space and Bloch-type spaces, Appl. Math. Comput. 218, 6 (2011), 2600-2618.

[24] S. STEVIĆ, Essential norm of some extensions of the generalized composition operators between $k$ th weighted-type spaces, J. Inequal. Appl. 2017, 220 (2017), 13 pp.

[25] S. STEVIĆ, A. K. SHARMA AND A. B HAT, Essential norm of products of multiplication composition and differentiation operators on weighted Bergman spaces, Appl. Math. Comput. 218, 6 (2011), 23862397.

[26] S. Stević, A. K. Sharma And A. Bhat, Products of multiplication composition and differentiation operators on weighted Bergman space, Appl. Math. Comput. 217, 20 (2011), 8115-8125.

[27] W. YANG, Generalized weighted composition operators from the $F(p, q, s)$ space to the Bloch-type space, Appl. Math. Comput. 218, 9 (2012), 4967-4972.

[28] Y. YU AND Y. LiU, On Stević type operator from $H^{\infty}$ space to the logarithmic Bloch spaces, Complex Anal. Oper. Theory 9, 8 (2015), 1759-1780.

[29] F. ZHANG AND Y. LiU, On a Stević-Sharma operator from Hardy spaces to Zygmund-type spaces on the unit disk, Complex Anal. Oper. Theory 12, 1 (2018), 81-100.

[30] L. Zhang AND H. ZENG, Weighted differentiation composition operators from weighted Bergman space to $n$th weighted space on the unit disk, J. Inequal. Appl. 2011, 65 (2011), 10 pp. 